\title{
Penyusunan norma tes fisik pencak silat remaja kategori tanding
}

\author{
Deny Pradana Saputro ${ }^{1 *}$, S. Siswantoyo ${ }^{1}$ \\ ${ }^{1}$ Program Studi Ilmu Keolahtragaan, Program Pascasarjana, Universitas Negeri Yogyakarta. \\ Jalan Colombo No. 1, Karangmalang, Yogyakarta, 55281, Indonesia \\ * Corresponding Author. Email: denypradanasaputro@gmail.com \\ Received: 2 January 2018; Revised: 8 February 2018; Accepted: 5 March 2018
}

\begin{abstract}
Abstrak
Penelitian ini bertujuan untuk: menyusun norma tes fisik pencak silat remaja kategori tanding. Penelitian ini menggunakan metode survei. Sampel yang digunakan dalam penelitian ini adalah atlet pencak silat remaja kategori tanding DIY yang berjumlah 42 atlet putra dan 46 atlet putri. Penyusunan norma menggunakan rumus norma 5 skala. Teknik analisis data menggunakan pearson correlation. Hasil penelitian berupa norma tes fisik pencak silat remaja kategori tanding yang terdiri dari 8 item tes, yaitu: fleksibilitas (sit and reach), kecepatan (sprint 30 meter), kekuatan lengan (push up 30 detik), kekuatan tungkai (wall sit test), kelincahan (side step), power tungkai (standing broad jump), daya tahan anaerobik (sprint 300 meter), dan daya tahan aerobik (multy fitness test). Tes dinyatakan valid dan reliabel dengan $\mathrm{p}<0,05$.
\end{abstract}

Kata Kunci: norma, tes pengukuran, kondisi fisik, remaja, pencak silat

\section{Norm drafting of pencak silat physical test for adolescent fighting category}

\begin{abstract}
This research aimed to know the norm of pencak silat physical test for adolescent fighting category. This research used survey method. The sample in this research was 42 men and 46 women of Pencak Silat adolescent fighting category. Data analysis used Pearson correlation.The result of the research was the norm of pencak silat physical test for adolescent fighting category, it was consisting of 8 test items: flexibility (sit and reach), speed (30 meters sprint), arm strength (30 seconds push up), leg strength (wall sit test), agility (side step), leg power (standing broad jump), anaerobic endurance (300 meters sprint) and (8) aerobic endurance (multy fitness test). The test was valid and reliable with $p<0,05$.
\end{abstract}

Keywords: norm, measurement test, physical condition, adolescent, pencak silat

How to Cite: Saputro, D., \& Siswantoyo, S. (2018). Penyusunan norma tes fisik pencak silat remaja kategori tanding. Jurnal Keolahragaan, 6(1), 1-10. doi:http://dx.doi.org/10.21831/jk.v6i1.17724

di) http://dx.doi.org/10.21831/jk.v6i1.17724

\section{PENDAHULUAN}

Indonesia merupakan negara yang unik. Unik dalam budaya, suku, ras dan berbagai bidang lainnya. Salah satu bidang lain tersebut adalah olahraga. Indonesia memiliki banyak jenis olahraga yang unik, dan keunikan tersebut mencirikhaskan Negara Indonesia. Salah satu olahraga yang mencirikhaskan Negara Indonesia adalah olahraga beladiri pencak silat. Walaupun di Negara lain juga memiliki olahraga beladiri masing-masing, akan tetapi beladiri pencak silat merupakan salah satu olahraga beladiri asli Indonesia yang berasal dari tanah melayu dan dipercaya sudah ada sejak zaman pra sejarah.
Hal itu dikarenakan dengan silat inilah bisa mempertahankan hidup dikerasnya kehidupan rimba (Lubis \& Wardoyo, 2014, p. 1).

Berdasarkan aspek-aspek yang terdapat di dalam pencak silat, PB IPSI menyatakan terdapat 4 aspek utama dalam pencak silat yaitu aspek mental spiritual, aspek beladiri, aspek seni dan aspek olahraga. Keempat aspek tersebut digambarkan dalam logo IPSI yang di dalamnya terdapat gambar trisula dengan ketiga ujungnya melambangkan unsur seni, beladiri dan olahraga, sedangkan gagang trisula melambangkan unsur mental spiritual (Maryono, 2000). 
Sebagai aspek mental spiritual, pencak silat lebih menekankan kepada pembentukan watak dan sikap kepribadian untuk dapat mengenali jati diri dan mengenali sang maha pencipta. Dengan demikian, pada aspek ini, pencak silat akan mampu membentuk watak dan sikap kepribadian yang baik dalam berhubungan dengan masyarakat, maupun dengan lingkungan sekitar.

Sedangkan sebagai aspek beladiri, pencak silat dipelajari dalam rangka untuk mempertahankan diri dari berbagai serangan orangorang yang bermaksud mencelakai atau melukai. Selain sebagai pertahanan diri, pencak silat juga bisa digunakan sebagai pertahanan bangsa dalam menjaga keutuhan NKRI. Hal ini terbukti dengan diajarkan pencak silat di kepolisian maupun TNI yang merupakan salah satu bentuk realisasi pencak silat sebagai alat yang digunakan untuk menjaga keutuhan NKRI.

Selanjutnya, sebagai seni pencak silat merupakan perwujudan dari kebudayaan yang direalisasikan dalam berbagai bentuk gerak dan irama. Gerak-gerak ini memiliki makna dan diselingi dengan irama-irama yang disesuaikan dengan gerak-gerak yang dilakukan. Diberbagai daerah di Indonesia, gerakan-gerakan tersebut dipertunjukkan pada setiap acara seperti acara pembukaan ataupun peresmian kegiatan, acara pernikahan dan juga dipertontonkan dimuka umum dengan berbagai maksud dan tujuan. Salah satunya adalah mengenalkan pencak silat itu sendiri dan juga sebagai hiburan masyakarat.

Hal yang tidak kalah penting dari penjelasan ketiga aspek sebelumnya yaitu aspek olahraga. Aspek olahraga merupakan aspek yang mengutamakan kebugaran jasmani maupun prestasi olahraga. Untuk dapat mencapai tingkat kebugaran jasmani yang baik dibutuhkan latihan pencak silat yang rutin. Sedangkan untuk dapat mencapai prestasi, dibutuhkan pembinaan secara berkelanjutan.

Harsono (2017) mengatakan bahwa sasaran dilakukannya pembinaan atau latihan bagi atlet adalah untuk meningkatkan keterampilan dan prestasi maksimal. Untuk dapat memperoleh itu diperlukan pembinaan terhadap beberapa aspek seperti fisik, teknik, taktik dan mental. Pembinaan yang dilakukan tersebut tentunya harus sesuai dengan tahap tumbuh kembang atlet itu sendiri. Hal ini bisa dilihat dari fase tumbuh kembang yang terjadi di fase usia dini, remaja dan dewasa.

Lebih lanjut berkaitan dengan fisik, Bompa \& Haff (2009, p. 57) mengatakan "The stronger the physical foundation, the greater the potential for developing technical, tactical, and psychological attributes". Penjelasan tersebut memberikan arti bahwa fondasi fisik yang kuat berpotensi baik untuk mengembangkan aspek teknik, taktik dan psikologi. Oleh karena diperlukan pembinaan terkait dengan fisik yang selanjutnya dilakukan pembinaan pada aspek lain seperti teknik, taktik dan mental.

Olahraga pencak silat merupakan salah satu cabang olahraga yang juga perlu dilakukan pembinaan terutama dalam aspek fisik terutana pada kategori tanding. Oleh karena itu, sebelumnya harus diketahui terlebih dahulu komponen biomotor apa saja yang dibutuhkan dalam cabang olahraga pencak silat. Hariono dalam Kuswanto (2016) menyatakan bahwa komponen biomotor yang dibutuhkan dalam cabang olahraga pencak silat yaitu kecepatan, ketahanan, kelentukan, kekuatan, dan koordinasi. Lebih lanjut dinyatakan Hariono (2005, p. 439) mengatakan bahwa predominan sistem energi yang digunakan dalam pencak silat kategori tanding adalah energi anaerobik alaktik dengan komposisi sistem energi predominan ATP-PC $73,75 \%$, LA-O2 16,25\% dan O2 sebesar $10 \%$. Selanjutnya, Lubis \& Wardoyo (2014, p. 148) menyatakan bahwa komponen yang diharapkan pada kategori tanding diantaranya kecepatan, reaksi, kelincahan, koordinasi, kekuatan, daya tahan, selanjutnya ditunjang dengan komponen keseimbangan, kelentukan dan ketepatan. Hal itu dikarenakan, pada kategori tanding perbandingan sistem energi yang dibutuhkan antara anaerob dan aerob kurang lebih 60:40.

Setelah dilakukan pembinaan terkait dengan aspek fisik, langkah selanjutnya untuk mengetahui apakah pembinaan yang dilakukan itu meningkatkan aspek yang dibina atau tidak maka perlu dilakukan tes. (Mardapi, 2017, p. 94) mengatakan bahwa tes merupakan salah satu bentuk instrumen yang digunakan untuk melakukan pengukuran. Sedangkan pengukuran dinyatakan Lacy (2011, p. 4), measurement is the process of collecting data on the property or attribute of interest". Measurement should be as precise, reliable, objective as possible, and the result should be expressed in a numerical form that indicates the quantity of the property or attribute measured. Pengukuran adalah proses pengumpulan data pada properti atau atribut yang terlibat. Pengukuran harus tepat, terpercaya, dan seobjektif mungkin, dan hasilnya harus dinyatakan dalam bentuk numerik yang menunjukkan kuantitas properti atau atribut 
yang diukur. Oleh karena pentingnya tes dan pengukuran tersebut, maka keberadaan tes dan pengukuran dalam bidang olahraga perlu diperhatikan.

Berdasarkan hasil penelitian pendahuluan yang peneliti lakukan dengan beberapa orang pelatih perguruan, pelatih pengda Yogyakarta, pelatih pengprov DIY dan ahli dibidang pencak silat melalui teknik wawancara, didapat data bahwa saat ini belum ada susunan tes fisik khusus pencak silat remaja kategori tanding. Selain belum tersusunnya tes fisik pencak silat remaja kategori tanding, norma tes fisiknya pun belum dibuat, sehingga selain penyusunan tes fisik pencak silat remaja kategori tanding, diperlukan pula penyusunan norma tes yang dipergunakan untuk mengklasifikasikan hasil tes fisik atlet pencak silat remaja kategori tanding.

Penelitian ini merupakan pelengkap dari penelitian sebelumnya yang disusun oleh Kuswanto (2016), yang menghasilkan penelitian berupa susunan tes fisik pencak silat dewasa kategori tanding. Hasil penelitian yang dilakukan menghasilkan 9 item tes fisik pencak silat dewasa kategori tanding. Item tes fisik tersebut diantanya adalah: (1) Fleksibilitas (Side Split), (2) Kecepatan (Sprint 40 Meter), (3) Power Lengan (Push Up 30 Detik), (4) Kekuatan Perut (Sit Up), (5) Kekuatan Punggung (Back Up), (6) Power Tungkai (Standing Triple Jump), (7) Kelincahan (Shuttle Run), (8) Daya tahan anaerobik (Sprint 300 meter), dan (9) Daya tahan aerobik (Bleep Test). Selanjutnya, dalam penelitian ini penulis ingin membuat norma tes fisik pencak silat remaja kategori tanding yang sebelumnya dilakukan penyusunan instrumen tes fisik pencak silat remaja kategori tanding dengan mengundang beberapa orang ahli yaitu ahli tumbuh kembang remaja, ahli kondisi fisik, dan ahli pencak silat.

Perlunya dibuat susunan tes fisik yang disertai norma tersebut mengingat remaja dan dewasa memiliki perbedaan dalam menguasai kemampuan fisik dan fungsional tubuhnya. Hal ini sesuai yang dikatakan oleh Monks dkk dalam Ali \& Asrori (2004, p. 9) yang menyatakan bahwa remaja masih belum mampu menguasai dan memfungsikan secara maksimal fungsi fisik maupun psikisnya. Oleh karena itu, agar instrumen yang dibuat tepat sasaran sesuai dengan tumbuh kembang remaja dan tentunya sesuai pula dengan karakteristik dari penggunaan fisik yang dibutuhkan dalam olahraga pencak silat kategori tanding, maka perlu dibuat susunan instrumen tes fisik pencak silat remaja kategori tanding. Selain itu, untuk memudahkan pelatih dalam mengetahui kondisi ataupun status fisik atlet remaja kategori tanding, instrumen tes fisik yang disusun perlu dilengkapi dengan norma. Norma disini merupakan rentang angka yang disertai keterangan status yang dibuat untuk mengetahui posisi kondisi atlet berada pada rentang yang mana. Norma tes yang dibuat bisa juga digunakan sebagai pedoman pelatih dalam pengambilan keputusan terhadap hasil tes. Dengan demikian, kondisi fisik atlet dapat dipantau pelatih dan dapat terus dilakukan peningkatan hingga mencapai kondisi fisik yang prima.

Selanjutnya, untuk memperjelas pembaca dalam memahami penelitian ini, penulis menekankan kembali bahwa tujuan utama dari penelitian ini adalah menyusun norma tes fisik pencak silat remaja kategori tanding, yang didahului dengan penyusunan instrumen tes fisik melalui Focus Group Discussion. Penyusunan instrumen tersebut juga perlu dilakukan karena saat ini susunan tes fisik pencak silat remaja kategori tanding belum tersusun dengan baik.

\section{METODE}

Penelitian ini menggunakan metode survei dengan cara melakukan tes fisik terhadap atlet pencak silat remaja kategori tanding. Penelitian ini dimulai pada bulan juni hingga September 2017. Penelitian ini dilaksanakan di Daerah Istimewa Yogyakarta.

Subjek dalam penelitian ini adalah atlet pencak silat remaja kategori tanding yang berada pada rentang usia 14-17 tahun. Pengambilan sampel menggunakan metode purposive sampling, yaitu metode pengambilan dengan pertimbangan tertentu. 88 atlet pencak silat (PPLP, PAB, POPNAS), PAB Sleman, Tim POSPEDA Wahid Hasyim, Sunan Pandanaran, Ali maksum dan Unit latihan Ali Maksum Krapyak sebagai testi untuk mendapatkan data tes yang selanjutnya diuji validitas dan reliabilitas intsrumen dan penyusunan norma.

Metode dalam penelitian ini menggunakan teknik survei dengan cara melakukan pengambilan data hasil tes fisik atlet pencak silat remaja kategori tanding sebanyak 88 atlet (42 atlet putra dan 46 atlet putri) wilayah DIY. Teknik pengumpulan data dalam penelitian ini dengan menggunakan wawancara, $F G D$ dan tes fisik. Data yang dikumpulkan dalam penelitian ini adalah dari hasil wawancara, FGD (forum group discussion), validasi ahli. Sedangkan data dari penelitian ini diperoleh dari tes pengukuran 
masing-masing komponen kondisi fisik fisik. Setelah FGD dilakukan kemudian uji validasi ahli untuk menentukan biomotor dan item tes apa saja yang diperlukan sesuai dengan karakteristik pencak silat kategori tanding.

Setelah mendapatkan informasi berkenaan dengan komponen biomotor yang dibutuhkan disertai intrumen yang tepat digunakan untuk mengukur masing-masing komponen biomotor dalam pencak silat kategori tanding khususnya remaja dilanjutkan dengan melakukan uji coba terhadap item tes fisik yang sudah didiskusikan. Penyusunan norma tes fisik yang digolongkan menjadi sangat baik, baik, sedang, kurang dan sangat kurang. Untuk perhitungannya dibutuhkan rerata dan simpangan baku.

\section{Teknik Analisis Data}

Teknik analisis data yang dipakai dalam penelitian ini adalah teknik analisis data secara kualitatif dan kuantitatif. Teknik analisis data secara kualitatif yaitu dengan mendiskribsikan wawancara dan Focus Group Discussion, sedangkan secara kuantitatif dengan perhitungan Pearson Correlation yang digunakan untuk menguji validitas dan reliabilitas instrument.

Nilai Standar Skala 5

Sebelum dilakukan penyusunan norma melalui nilai standar 5 terlebih dahulu dilakukan pengambilan data tes fisik atlet pencak silat remaja kategori tanding sebanyak 88 atlet. Setelah data didapat barulah disusun norma tes fisik pencak silat remaja kategori tanding.

Penyusunan skor skala untuk masingmasing item tes fisik yaitu dengan mengubah raw skor (angka kasar) kedalam nilai standar skala 5 yaitu A (sangat baik), B (Baik), C (cukup), D (sedang) dan E (sangat kurang). Standar skala 5 patokan yang digunakan adalah:

Tabel 1. Rumus Nilai Standar 5 Skala (Sudijono, 2005, p. 175)

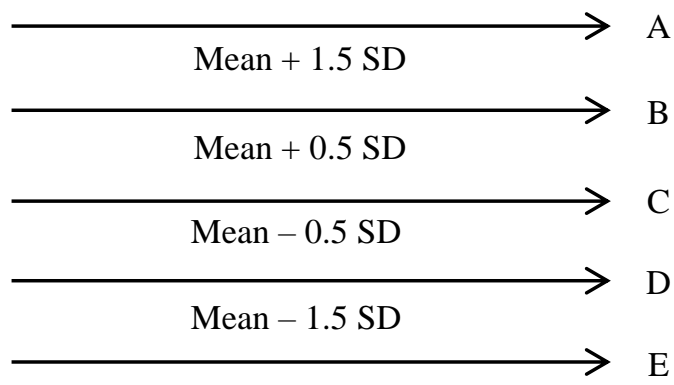

Dari patokan yang ada tersebut selanjutnya bisa dibuat rumus untuk mengakategorikan hasil tes fisik pencak silat remaja kategori tanding yang dapat dilihat pada Tabel 2 dan Tabel 3.

Tabel 2. Rumus Pengkategorian Klasifikasi Norma Untuk Tes Fisik Pencak Silat Kategori Tanding.

\begin{tabular}{ccc}
\hline Rumus & Kategori & Nilai \\
\hline$>\mathrm{M}+(1.5 \mathrm{SD})$ & A atau & 5 \\
& $\begin{array}{c}\text { Sangat Baik } \\
\text { B atau } \\
\text { Baik }\end{array}$ & 4 \\
$\mathrm{M}+(0.5 \mathrm{SD}) \mathrm{S} / \mathrm{D} \mathrm{M}+(1.5 \mathrm{SD})$ & $\begin{array}{c}\text { C atau } \\
\text { Sedang }\end{array}$ & 3 \\
$\mathrm{M}-(0.5 \mathrm{SD}) \mathrm{S} / \mathrm{D} \mathrm{M}+(0.5 \mathrm{SD})$ & $\begin{array}{c}\text { D atau } \\
\text { Kurang }\end{array}$ & 2 \\
& E atau & 1 \\
& Sangat Kurang & \\
\hline
\end{tabular}

Untuk tes fisik kecepatan 30 meter dan daya tahan anaerobik rumus yang digunakan seperti terlihat pada Tabel 3.

Tabel 3. Rumus Pengkategorian Klasifikasi Norma untuk Tes Fisik Kecepatan 30 Meter dan Daya Tahan Anaerobik

\begin{tabular}{ccc}
\hline Rumus & Kategori & Nilai \\
A atau & $(1.5 S D)$ & 5 \\
& $\begin{array}{c}\text { Sangat Baik } \\
\text { B atau } \\
\text { Baik }\end{array}$ & 4 \\
$\mathrm{M}-($ (1.5SD) S/D M - (0.5SD) & $\begin{array}{c}\text { C atau } \\
\text { Sedang } \\
\text { D atau }\end{array}$ & 3 \\
K $+(0.5 \mathrm{SD}) \mathrm{S} / \mathrm{D} \mathrm{M}+(1.5 \mathrm{SD})$ & 2 \\
$\mathrm{M}+(1.5 \mathrm{SD})<$ & $\begin{array}{c}\text { E atau } \\
\text { Sangat Kurang }\end{array}$ & 1 \\
\hline
\end{tabular}

Keterangan

M: Mean (rata-rata)

SD: Standar Deviasi

Setelah dilakukan pengkategorian klasifikasi norma untuk masing-masing item tes fisik, langkah selanjutnya agar seluruh item tes yang memiliki satuan hitungan yang berbeda bisa dicari skor totalnya maka perlu disamakan agar dapat dijumlahkan secara keseluruhan. Oleh karena itu masing-masing norma item tes perlu di maknai dengan angka atau nilai 1-5 dengan 1 (E atau sangat kurang), 2 (D atau kurang), 3 (C atau sedang), 4 (B atau baik) dan 5 (A atau sangat baik). Sebagai contoh bisa dlihat pada tabel 3 dibawah ini.

Uji Validitas dan Reliabilitas.

Uji validitas dan reliabilitas dilakukan dengan melakukan pengambilan data tes fisik pencak silat remaja kategori tanding sebanyak 56 siswa silat 27 laki-laki dan 29 perempuan. 
Setelah didapat data tes fisik selanjutnya dikakukan perhitungan pearson correlation untuk mengetahui nilai validitas dan reliabilitas instrumen.

\section{HASIL DAN PEMBAHASAN}

Hasil dan pembahasan penelitian ini terdiri dari hasil Focus Group Discussion (FGD) terkait penyusunan instrumen tes fisik pencak silat remaja kategori tanding. Selanjutnya, berkaitan dengan hasil uji validitas dan reliabilitas, hasil uji efektifitas produk dan penyusunan norma tes fisik.

\section{Hasil Focus Group Discussion (FGD)}

Adapun hasil dari $F G D$ adalah sebagai berikut: fleksibilitas, instrumen tes yang digunakan adalah sit and reach; kecepatan, instrumen tes yang digunakan adalah; lari 30 meter; kekuatan otot lengan, instrumen tes yang digunakan adalah push up 30 detik; kekuatan tungkai, instrumen tes yang digunakan adalah wall sit test; kelincahan, instrumen tes yang digunakan adalah side step; power tungkai, instrumen tes yang digunakan adalah standing broad jump; daya tahan anaerobik, instrumen tes yang digunakan adalah lari 300 meter; daya tahan aerobik, instrumen tes yang digunakan adalah multy fitness test.

\section{Kelentukan}

Berkaitan dengan kelentukan, Bompa \& Carrera (2015, p. 67) menyatakan Flexibility refers to the range of motion around a joint. Improving flexibility is a fundamental element of a young athlete's training program because good flexibility enables the athlete to perform various movements and skills easily and helps prevent injury. Selanjutnya Sukadiyanto \& Muluk (2011, p. 137) menyatakan bahwa fleksibilitas dibagi menjadi dua yaitu, fleksibilitas statis dan fleksibitas dinamis. Pada fleksibiltas statis ditentukan oleh ukuran dan luas gerak (range of motion) satu atau beberapa persendian. Sedangkan pada fleksibilitas dinamis merupakan kemampuan seseorang dalam bergerak dengan kecepatan yang tinggi.

Fleksibilitas merupakan salah satu komponen kondisi fisik yang mempunyai peranan penting bagi olahragawan maupun non olahragawan. Begitu pula dalam pertandingan pencak silat kategori tanding juga harus memiliki fleksibilitas yang baik. Dengan adanya dukungan fleksibiltas yang baik seorang pesilat akan mampu melakukan gerakan seleluasa mungkin untuk melakukan serangan-serangan (pukulan, tendangan, tangkapan, guntingan maupun bantingan) maupun hindaran terhadap lawan. Tanpa adanya dukungan fleksibiltas, tentu maka seorang atlet silat tidak dapat melakukan gerakan dengan leluasa karena terganggu dengan terbatasnya range of motion.

\section{Kecepatan}

Kecepatan adalah kemampuan otot atau sekelompok otot untuk menjawab rangsang dalam waktu secepat (sesingkat) mungkin. Kecepatan sebagai hasil perpaduan dari panjang ayunan tungkai dan jumlah langkah. Gerakan panjang ayunan dan jumlah langkah merupakan serangkaian gerak yang sinkron dan kompleks dari sistem neuromuskuler. Usia remaja merupakan usia yang bisa dilakukan pembinaan terkait dengan peningkatan kecepatan. Some experiments on boys and girls aged between 7.6 and 10.3 years have shown a significant improvement in running performance (up to 18\%), but without an obvious increase in VO2 max (Borms, 1986, p. 7).

Kecepatan merupakan salah satu komponen dasar bimotor yang diperlukan dalam cabang olahraga pencak silat terutama pencak silat kategori tanding. Segala aktifitas olahraga baik yang bersifat permainan, perlombaan, maupun pertandingan selalu memerlukan komponen biomotor kecepatan. Begitu juga dalam olahraga pencak silat kategori tanding. Tingkat kemampuan kecepatan seseorang sangat ditentukan oleh beberapa faktor, antara lain ditentukan oleh keturunan, waktu reaksi, kekuatan, teknik speed, elastisitas otot, jenis otot, konsentrasi dan kemauan (Mylsidayu \& Kurniawan, 2015, pp. 116-118). Olahraga cabang lari $100 \mathrm{~m}$, sprint performance is dependent on multiple factors and we have categorized them based on environmental, mechanical/equipment, biomechanical and psycho-physiological labels (Majumdar \& Robergs, 2011, p. 481).

Selain faktor tersebut jenis otot juga berpengaruh terhadap tingkat kecepatan yang dimiliki seseorang. Untuk itu kecepatan merupakan salah satu unsur biomotor yang harus dilatihkan dalam upaya mendukung pencapaian prestasi olahragawan. Pencak silat merupakan salah satu olahraga yang membutuhkan kecepatan. Serangan-serangan yang dilakukan baik itu tendangan, pukulan, guntingan maupun beberpa teknik serangan lain harus dilakukan dengan cepat agar lawan tidak sempat untuk mengantisipasi serangan. 


\section{Kekuatan}

Pengertian kekuatan secara umum adalah kemampuan otot atau sekelompok otot untuk mengatasi beban atau tahanan. Pengertian secara fisiologi, kekuatan adalah kemampuan neuromusculer untuk mengatasi tahanan beban luar dan beban dalam. Kekuatan otot adalah kemampuan sekelompok otot untuk melawan beban dalam satu usaha. Strength improves as muscle mass increases with age. Peak strength usually is attained by age 20 in women and between ages 20 and 30 in men (Kenney, Wilmore, \& Costill, 2015, p. 430). Adapun manfaat dari latihan kekuatan bagi olahragawan diantaranya untuk: meningkatkan kemampuan otot dan jaringan, mengurangi cedera pada olahragawan, meningkatkan prestasi, terapi pada rehabilitasi penguatan otot dan membantu mempelajari atau penguasaan teknik (Sukadiyanto \& Muluk, 2011, p. 90). Strength is among the most important components for almost every sport. Strength training aims to increase the athlete's competition performance by: (a) enhancing the neural component of muscle contraction, and (b) augmenting the muscle-fibre size (Whyte, 2006, p. 17). Selanjutnya terkait dengan kekuatan di masa remaja, During adolescence, static and explosive strength and also speed of limb movement are clearly related to maturity status. From the ages of 13 to 14 years, early maturers perform, on average, better than late maturers. However, it is difficult to conclude that there is a causal influence of maturity on motor ability, because other factors, such as height and weight, can confound the results (Lefevre, Beunen, Steens, Claessens, \& Renson, 1990, p. 432).

Kekuatan merupakan komponen biomotor yang sangat diperlukan untuk meningkatkan daya tahan otot dalam mengatasi beban selama berlangsungnya aktifitas olahraga. Secara fisiologi, kekuatan adalah kemampuan neuromuscular untuk mengatasi tahanan beban untuk mengatasi tahanan beban luar dan beban dalam. Adapun manfaat dari latihan kekuatan adalah untuk meningkatkan kemampuan otot dan jaringan, mengurangi dan menghindari terjadinya cedera, meningkatkan prestasi, terapi dan rehabilitasi cedera pada otot dan membantu dalam penguasaan teknik. Dengan demikian, kekuatan juga merupakan komponen biomotor yang sangat penting dalam olahraga pencak silat.
Ahirnya, kekuatan akan dapat meningkatkan prestasi seorang atlit pencak silat kategori tanding yang tentu dalam hal ini perlu dukungan dari hal yang lainnya seperti kemampuan teknik, taktik dan psikologi yang matang.

\section{Kelincahan}

Memiliki kelincahan yang baik bagi seorang pesilat sangat menguntungkan karena seorang pesilat akan mampu melakukan serangan, hindaran maupun melakukan keduanya sekaligus dengan baik. Hal itu dikarenakan kelincahan merupakan komponen penting yang dibutuhkan oleh hampir seluruh cabang olahraga termasuk pencak silat. Kelincahan itu sendiri merupakan kombinasi dari beberapa komponen fisik lain seperti kecepatan, koordinasi, fleksibilitas, dan power (Bompa \& Buzzichelli, 2015, p. 8). Orang yang lincah adalah orang yang mempunyai kemampuan untuk mengubah arah dan posisi tubuh dengan cepat dan tepat, tanpa kehilangan keseimbangan dan kesadaran akan posisi tubuhnya disaat sedang bergerak (Suharjana, 2013, p. 151). Dengan demikian, memiliki kelincahan yang baik bagi seorang pesilat kategori tanding adalah sesuatu hal yang sangat penting.

\section{Power}

Power, defined as the rate of doing work (Dawes \& Roozen, 2012, p. 9). Untuk mengukur power biasanya tes yang dilakukan adalah standing broad jump or vertical jump test. Dalam olahraga pencak silat kategori tanding, power merupakan hal yang sangat dibutuhkan saat melakukan serangan. Power berhubungan dengan kekuatan dan kecepatan. Ada banyak penelitian terkait dengan power itu sendiri. Beberapa hal yang biasa dibahas dalam penelitian tersebut terkait dengan bagaimana caranya meningkatkan power, selanjutnya, menghubungkan biomotor power dengan kemampuan sesorang dalam melakukan sesuatu, dan lain sebagainya. Sebagai salah satu contoh terkait dengan hal tersebut berhubungan dengan sebuah penelitian yang menghasilkan sebuah kesimpulan bahwa dalam rangka meningkatkan power tungkai pesilat remaja dapat digunakan model latihan alternatif yaitu latihan pliometrik (Siswantoyo, 2014, p. 80).

\section{Daya Tahan}

Istilah daya tahan atau ketahanan ditinjau dari kemampuan kerja otot adalah kemampuan 
otot yang berkerja dalam waktu tertentu. Daya tahan otot berarti kemampuan untuk mempertahankan otot dalam melawan beban (Suharjana, 2013, p. 77). Dalam dunia olahraga dikenal sebagai kemampuan peralatan organ tubuh olahragawan untuk melawan kelelahan selama berlangsungnya aktifitas atau kerja. Kelelahan selalu terkait dengan lama kerja (durasi) dan intensitas kerja. Semakin lama durasi latihan dan semakin tinggi intensitas kerja yang dapat dilakukan oleh seorang olahragwan, maka olahragawan itu dikatakan memiliki ketahanan yang baik. Ketahanan dipengaruhi oleh beberapa faktor, yaitu: sistem pusat saraf, kemauan (motivasi) olahragawan, kapasitas aerobik, kapasitas anaerobik, kecepatan cadangan, intensitas, frekuensi dan durasi latihan, keturunan, umur dan jenis kelamin (Sukadiyanto \& Muluk, 2011, p. 60). Dengan memiliki daya tahan yang baik yang diintegrasikan dengan komponen biomotor lain, maka seorang pesilat akan mampu mempertahankan dirinya dari kehilangan kelelahan yang berarti. Kondisi yang demikian akan menguntungkan bagi seorang pesilat kategori tanding.

\section{Hasil Uji Validitas dan Reliabilitas}

Untuk mengetahui hasil uji validitas dan reliabilitas instrumen tes fisik pencak silat remaja kategori tanding perlu dilakukan perhitungan dengan menggunakan perhitungan pearson correlation.

Pengambilan data tes fisik untuk uji reliabilitas dilakukan dua kali (test-retest) dengan instrumen tes dan subjek penelitian yang sama. Untuk mencari nilai kedua uji tersebut dicari dengan menggunakan aplikasi spss 16. Hasil pengujian validitas dan reliabilitas instrumen meliputi kelentukan (sit and reach), kecepatan (lari 30 meter), kekuatan lengan (push up 30 detik), kekuatan tungkai (wall sit test), kelincahan (side step), power tungkai (standing broad jump), daya tahan anaerobik (lari 300 meter), dan daya tahan aerobik (multy fitness test). Berikut ini akan di dijabarkan hasil dari uji validitas dan reliabilitas yang sudah dilakukan perhitungan menggunakan perhitungan pearson correlation. Silahkan dilihat pada Tabel 4 sampai pada Tabel 7.

Tabel 4 menunjukkan hasil uji validitas menunjukkan nilai $\mathrm{p}<0,05$. Hasil tersebut menyimpulkan bahwa keseluruhan instrumen tes fisik pencak silat remaja putra kategori tanding dinyatakan valid.
Tabel 5 menunjukkan hasil uji validitas menunjukkan nilai $\mathrm{p}<0,05$. Hasil tersebut menyimpulkan bahwa keseluruhan instrumen tes fisik pencak silat remaja putri kategori tanding dinyatakan valid.

Tabel 6 menunjukkan hasil uji validitas menunjukkan nilai $\mathrm{p}<0,05$. Hasil tersebut menyimpulkan bahwa keseluruhan instrumen tes fisik pencak silat remaja putra kategori tanding dinyatakan reliabel.

Tabel 7 menunjukkan hasil uji validitas menunjukkan nilai $\mathrm{p}<0,05$. Hasil tersebut menyimpulkan bahwa keseluruhan instrumen tes fisik pencak silat remaja putri kategori tanding dinyatakan reliabel.

Tabel 4. Hasil Uji Validitas Intrumen Tes Fisik Pencak Silat Remaja Putra Kategori Tanding

\begin{tabular}{lcc}
\hline \multicolumn{1}{c}{ Item Tes Fisik } & Probabilitas & Keterangan \\
\hline sit and reach & & Valid \\
$30 \mathrm{~m}$ sprint & & Valid \\
30 second push up & & Valid \\
wall sit test & & Valid \\
wall sit test & $\mathrm{P}<0,05$ & Valid \\
side step & & Valid \\
standing broad jump & & Valid \\
300 m sprint & & Valid \\
multy fitness test & & Valid \\
\hline
\end{tabular}

Tabel 5. Hasil Uji Validitas Intrumen Tes Fisik Pencak Silat Remaja Putri Kategori Tanding

\begin{tabular}{lcc}
\hline \multicolumn{1}{c}{ Item Tes Fisik } & Probabilitas & Keterangan \\
\hline sit and reach & & Valid \\
30 m sprint & & Valid \\
30 second push up & & Valid \\
wall sit test & & Valid \\
wall sit test & $\mathrm{P}<0,05$ & Valid \\
side step & & Valid \\
standing broad jump & & Valid \\
300 m sprint & & Valid \\
multy fitness test & & Valid \\
\hline
\end{tabular}

Tabel 6. Hasil Uji Reliabilitas Intrumen Tes Fisik Pencak Silat Remaja Putra Kategori Tanding

\begin{tabular}{lcc}
\hline \multicolumn{1}{c}{ Item Tes Fisik } & Probabilitas & Keterangan \\
\hline sit and reach & & Reliabel \\
30 m sprint & & Reliabel \\
30 second push up & & Reliabel \\
wall sit test & & Reliabel \\
wall sit test & $\mathrm{P}<0,05$ & Reliabel \\
side step & & Reliabel \\
standing broad jump & & Reliabel \\
300 m sprint & & Reliabel \\
multy fitness test & & Reliabel \\
\hline
\end{tabular}


Jurnal Keolahragaan 6 (1), 2018 - 8

Deny Pradana Saputro, S. Siswantoyo

Tabel 7. Hasil Uji Reliabilitas Intrumen Tes Fisik Pencak Silat Remaja Kategori Tanding Putri

\begin{tabular}{lcc}
\hline \multicolumn{1}{c}{ Item Tes Fisik } & Probabilitas & Keterangan \\
\hline sit and reach & & Reliabel \\
$30 \mathrm{~m}$ sprint & & Reliabel \\
30 second push up & & Reliabel \\
wall sit test & & Reliabel \\
wall sit test & $\mathrm{P}<0,05$ & Reliabel \\
side step & & Reliabel \\
standing broad jump & & Reliabel \\
300 m sprint & & Reliabel \\
multy fitness test & & Reliabel \\
\hline
\end{tabular}

\section{Hasil Penyusunan Norma}

Adapun hasil penyusunan norma tes fisik pencak silat remaja kategori tanding dapat dilihat pada Tabel 8 sampai Tabel 17. Hasil dari penyusunan norma ini dapat dilakukan setelah dilakukan tes fisik dengan sampel atlet silat remaja usia 14-17 tahun yang berjumlah 88 atlet dengan 42 atlet berjenis kelamin laki-laki dan 46 atlet berjenis kelamin perempuan. Rumus yang digunakan dalam rangka mendapatkan susunan norma tersebut seperti pada Tabel 2 dan 3 .

Tabel 8. Norma Kelentukan (Sit And Reach)

\begin{tabular}{|c|c|c|}
\hline \multicolumn{3}{|c|}{ Sit And Reach $(\mathrm{Cm})$} \\
\hline Putra & Putri & Nilai \\
\hline $45.6<$ & $47.44<$ & 5 \\
\hline $40.6 \mathrm{~S} / \mathrm{D} 45.6$ & $42.46 \mathrm{~S} / \mathrm{D} 47.44$ & 4 \\
\hline $35.61 \mathrm{~S} / \mathrm{D} 40.6$ & $37.48 \mathrm{~S} / \mathrm{D} 42.46$ & 3 \\
\hline 30.62 S/D 35.61 & $32.50 \mathrm{~S} / \mathrm{D} 37.48$ & 2 \\
\hline$<30.62$ & $<32.50$ & 1 \\
\hline
\end{tabular}

Tabel 9. Norma Kecepatan (Lari 30 Meter)

\begin{tabular}{ccc}
\hline \multicolumn{3}{c}{ Lari 30 Meter (Detik) } \\
\hline Putra & Putri & Nilai \\
\hline$<4.2$ & $<5.1$ & 5 \\
4.2 S/D 4.7 & 5.1 S/D 5.7 & 4 \\
4.7 S/D 5.2 & 5.7 S/D 6.2 & 3 \\
5.2 S/D 5.7 & 6.2 S/D 6.8 & 2 \\
5.7 < & $6.8<$ & 1 \\
\hline
\end{tabular}

Tabel 10. Norma Kekuatan Lengan (Push Up 30 Detik)

\begin{tabular}{ccc}
\hline \multicolumn{3}{c}{ Push Up 30 Detik (Kali) } \\
\hline Putra & Putri & Nilai \\
\hline $39<$ & $33<$ & 5 \\
30 S/D 39 & 27 S/D 33 & 4 \\
21 S/D 30 & 20 S/D 27 & 3 \\
12 S/D 21 & 14 S/D 20 & 2 \\
$<$ 12 & $<14$ & 1 \\
\hline
\end{tabular}

Tabel 11. Norma Kekuatan Tungkai Putra (Wall Sit Test)

\begin{tabular}{|c|c|c|}
\hline \multicolumn{3}{|c|}{ Wall Sit Test (Detik) } \\
\hline \multicolumn{2}{|c|}{ Putra } & \multirow{2}{*}{ Nilai } \\
\hline Kanan & Kiri & \\
\hline $60,2<$ & $59,6<$ & 5 \\
\hline 43,4 S/D 60,2 & $43,3 \mathrm{~S} / \mathrm{D} 59,6$ & 4 \\
\hline $26,6 \mathrm{~S} / \mathrm{D} 43,4$ & $27,1 \mathrm{~S} / \mathrm{D} 43,3$ & 3 \\
\hline $9,8 \mathrm{~S} / \mathrm{D} 26,6$ & $10,8 \mathrm{~S} / \mathrm{D} 27,1$ & 2 \\
\hline$<9,8$ & $<10,8$ & 1 \\
\hline
\end{tabular}

Tabel 12. Norma Kekuatan Tungkai Putra (Wall Sit Test)

\begin{tabular}{|c|c|c|}
\hline \multicolumn{3}{|c|}{ Wall Sit Test (Detik) } \\
\hline \multicolumn{2}{|c|}{ Putri } & \multirow{2}{*}{ Nilai } \\
\hline Kanan & Kiri & \\
\hline $43,4<$ & $52.8<$ & 5 \\
\hline $29,8 \mathrm{~S} / \mathrm{D} 43,4$ & 35,4 S/D 52.8 & 4 \\
\hline $16,3 \mathrm{~S} / \mathrm{D} 29,8$ & $18 \mathrm{~S} / \mathrm{D} 35,4$ & 3 \\
\hline $2,7 \mathrm{~S} / \mathrm{D} 16,3$ & $0,7 \mathrm{~S} / \mathrm{D} 18$ & 2 \\
\hline$<2,7$ & $<0,7$ & 1 \\
\hline
\end{tabular}

Tabel 13. Norma Kelincahan (Side Step)

\begin{tabular}{ccc}
\hline \multicolumn{3}{c}{ Side Step (Kali) } \\
\hline Putra & Putri & Nilai \\
\hline 25 & $26<$ & 5 \\
23 S/D 25 & 23 S/D 33 & 4 \\
22 S/D 23 & 20 S/D 23 & 3 \\
20 S/D 22 & 17 S/D 20 & 2 \\
$<20$ & $<17$ & 1 \\
\hline
\end{tabular}

Tabel 14. Norma Power Tungkai (Standing Broad Jump)

\begin{tabular}{ccc}
\hline \multicolumn{3}{c}{ Standing Broad Jump $(\mathbf{C m})$} \\
\hline Putra & Putri & Nilai \\
\hline 240,4 < & $204,1<$ & 5 \\
213,4 S/D 240,4 & 181,6 S/D 204,1 & 4 \\
186,4 S/D 213,4 & 159,2 S/D 181,6 & 3 \\
159,4 S/D 186,4 & 136,8 S/D 159,2 & 2 \\
$<$ 159,4 & $<136,8$ & 1 \\
\hline
\end{tabular}

Tabel 15. Norma Daya Tahan Anaerobik (Lari 300 Meter)

\begin{tabular}{ccc}
\hline \multicolumn{3}{c}{ Lari 300 Meter (Detik) } \\
\hline Putra & Putri & Nilai \\
\hline$<51,0$ & $<62,6$ & 5 \\
51,0 S/D 60,0 & 62,6 S/D 75,0 & 4 \\
60,0 S/D 69,0 & 75,0 S/D 87,3 & 3 \\
69,0 S/D 78,0 & 87,3 S/D 99,7 & 2 \\
$78,0<$ & $99,7<$ & 1 \\
\hline
\end{tabular}


Tabel 16. Norma Daya Tahan Aerobik (Multy Fitness Test/Beep Test)

\begin{tabular}{|c|c|c|}
\hline \multicolumn{3}{|c|}{ Multy Fitness Test/Beep Test (Level) } \\
\hline Putra & Putri & Nilai \\
\hline $8 / 9<$ & $6 / 10<$ & 5 \\
\hline 7/7 S/D 8/9 & 5/4 S/D 6/10 & 4 \\
\hline 6/4 S/D 7/7 & 3/6 S/D 5/4 & 3 \\
\hline $5 / 1 \mathrm{~S} / \mathrm{D} 6 / 4$ & $1 / 7 \mathrm{~S} / \mathrm{D} 3 / 6$ & 2 \\
\hline$<5 / 1$ & $<1 / 7$ & 1 \\
\hline
\end{tabular}

\section{Norma Keseluruhan Tes}

Norma keseluruhan tes ditetapkan dengan 5 standar skala. Tes harus dilaksanakan secara keseluruhan, sehingga jumlah item tes yang harus dilaksanakan atlet adalah 9 \{tes kelentukan, tes kecepatan, tes kekuatan lengan, tes kekuatan tungkai (dihitung dua tes yaitu tes kekuatan tungkai kanan dan tes kekuatan tungkai kiri), tes kelincahan, tes power tungkai, tes daya tahan anaerobik dan tes daya tahan aerobik\}. Nilai minimal yang diperoleh atlet pada tiap item tes adalah 1 maksimal 5. Jumlah item tes dihitung 9. Sehingga nilai minimal yang didapat atlet untuk seluruh item tes adalah 9 dan maksimal adalah 45 .

Dari penjelasan tersebut bisa dicari rentang $(\mathrm{R})$ untuk menyusun norma tes secara kese-luruhan. Perhitungannya sebagai berikut:

$\mathrm{R}=$ Nilai maksimal-Nilai minimal

$\mathrm{R}=45-9$

$=36$

Banyak kelas ditetapkan 5, sehingga diperoleh panjang kelas $(p)=36 / 5$, yaitu 7,2 . Dari perhitungan tersebut bisa disusun rentang nilai tes yang bisa digunakan untuk atlet putra maupun putri seperti Tabel 17:

Tabel 17. Norma Tes Keseluruhan

\begin{tabular}{cc}
\hline Putra Dan Putri & Kategori \\
\hline 37,8 S/D 45 & Sangat Baik \\
30,5 S/D 37,8 & Baik \\
23,4 S/D 30,5 & Sedang \\
16,2 S/D 22,4 & Kurang \\
9 S/D 16,2 & Sangat Kurang \\
\hline
\end{tabular}

\section{SIMPULAN DAN SARAN}

\section{Simpulan}

Penelitian ini menghasilkan susunan norma tes fisik pencak silat remaja kategori tanding melalui studi pendahuluan dan $F G D$ yang terdiri dari 8 item tes fisik. Item-item tersebut diantaranya adalah adalah (1) tes kelentukan menggunakan instrumen sit and reach, (2) tes kecepatan menggunakan instru- men sprint 30 meter, (3) tes kekuatan lengan menggunakan instrumen push up 30 detik, (4) tes kekuatan tungkai (kanan dan kiri) menggunakan instrumen wall sit test, (5) tes kelincahan menggunakan instrumen side step, (6) tes power tungkai menggunakan instrumen standing broad jump, (7) tes daya tahan anaerobik menggunakan instrumen sprint 300 meter, dan (8) tes daya tahan aerobik menggunakan instrumen multy fitness fitness. Item tes tersebut disertai dengan susunan norma masing-masing item tes dan tes secara keseluruhan,

Hasil uji validitas dan reliabilitas masingmasing instrumen tes fisik pencak silat remaja kategori tanding memiliki nilai $\mathrm{p}<0.05$. Hal ini menunjukkan bahwa seluruh instrumen tes fisik valid dan reliabel.

\section{Saran}

Saran pemanfaatan produk yang dihasilkan dari penelitian ini agar susunan instrumen tes fisik pencak silat remaja kategori tanding yang disertai dengan norma tes dapat dimanfaatkan oleh pelatih untuk mengevaluasi status kondisi fisik atlet pencak silat remaja kategori tanding usia 14-17 tahun. Selain itu diperlukan penelitian lebih lanjut dalam rangka mempermudah pengolahan hasil tes dari manual menjadi otomatis dengan memanfaatkan teknologi yang ada.

\section{DAFTAR PUSTAKA}

Ali, M., \& Asrori, M. (2004). Psikologi remaja perkembangan peserta didik. Jakarta: Bumi Aksara.

Bompa, T., \& Buzzichelli, C. (2015). Periodization training for sports. Human kinetics.

Bompa, T., \& Carrera, M. (2015). Conditioning young athletes. Human Kinetics.

Bompa, T. O., \& Haff, G. (2009). Periodization: Theory and methodology of training. Human Kinetics.

Borms, J. (1986). The child and exercise: An overview. Journal of Sports Sciences, 4(1), https://doi.org/10.1080/026404186087320 93

Dawes, J., \& Roozen, M. (2012). Developing agility and quickness. Human Kinetics.

Hariono, A. (2005). Predominan sistem energi dalam pencak silat kategori tanding. Majalah Ilmiah Olahraga, 11(3), 427. 
Harsono. (2017). Kepelatihan olahraga teori dan metodologi. Bandung: PT. Remaja Rosdakarya.

Kenney, W. L., Wilmore, J. H., \& Costill, D. L. (2015). Physiology of sport and exercise.

Kuswanto, C. W. (2016). Penyusunan tes fisik atlet pencak silat dewasa kategori tanding. Jurnal Keolahragaan, 4(2), 145. https://doi.org/10.21831/jk.v4i2.6423

Lacy, A. C. (2011). Measurement and evaluation in physical education and exercise science. Pearson Benjamin Cummings.

Lefevre, J., Beunen, G., Steens, G., Claessens, A., \& Renson, R. (1990). Motor performance during adolescence and age thirty as related to age at peak height velocity. Annals of Human Biology, 17(5), 423-435.

https://doi.org/10.1080/030144690000012 02

Lubis, J., \& Wardoyo, H. (2014). Pencak silat. Bandung: PT Raja Grafindo Persada.

Majumdar, A. S., \& Robergs, R. A. (2011). The science of speed: Determinants of performance in the $100 \mathrm{~m}$ sprint. International Journal of Sports Science \&
Coaching, 6(3), 479-493. Retrieved from http://journals.sagepub.com/doi/pdf/10.12 60/1747-9541.6.3.479

Mardapi, D. (2017). Pengukuran penilaian dan evaluasi pendidikan. Yogyakarta: Nuha Medika.

Maryono, O. (2000). Pencak silat merentang waktu. Yogyakarta: Galang Press.

Mylsidayu, A., \& Kurniawan, F. (2015). Ilmu kepelatihan dasar. Bandung: Alfabeta.

Siswantoyo, S. (2014). Peningkatan power tungkai pesilat remaja melalui latihan pliometrik. Jurnal Cakrawala Pendidikan, 1(1). https://doi.org/10.21831/cp.v1i1.1864

Sudijono, A. (2005). Pengantar statistik pendidikan. Jakarta: PT Raja Grafindo Persada.

Suharjana, S. (2013). Kebugaran jasmani. Yogyakarta: Jogja Global Media.

Sukadiyanto \& Muluk, D. (2011). Pengantar teori dan metodologi melatih fisik. Bandung: Lubuk Agung.

Whyte, G. P. (2006). The physiology of training. Churchill Livingstone/Elsevier. 